The BMJ

emahase@bmj.com

Cite this as: BMJ 2020;370:m3261 http://dx.doi.org/10.1136/bmj.m3261 Published: 21 August 2020

\section{PATIENT SERVICES}

\section{Covid-19: Charity cuts could put the NHS under even more pressure}

\section{As the UK's third sector faces a major funding crisis due to the pandemic, essential patient services-from social prescribing to end of life care-could face cuts or closure. The whole of the NHS will feel the impact, reports Elisabeth Mahase}

\section{Elisabeth Mahase}

"This year alone we think our fundraising income is going to fall by nearly one third, leaving a gap of

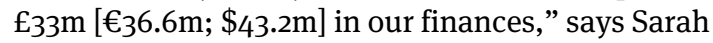
Wells, consultant in palliative care and medical director at the Marie Curie Hospice in the West Midlands. "Any reduction in our service is going to have a direct knock-on effect on our partners in the NHS, which will have to pick up any unmet need now and growing demand in the future.

"That is a huge concern."

This is the situation facing many UK charities today. Unable to fundraise as they did before the pandemic, forced to cancel already planned events, and still trying to provide support to their communities, many are having to decide what they can still afford to do, not just in the coming months but in the years ahead.

A survey of UK charities-carried out by the Institute of Fundraising, the Charity Finance Group, and the National Council for Voluntary Organisations and published in June-found that the sector expected a $£ 12.4 \mathrm{bn}$ loss of income this year because of the pandemic. $^{1}$

Caron Bradshaw, chief executive of the Charity Finance Group, says, "Charities are telling us that they are planning for a substantial decline to their incomes for the year ahead, at a time when the need for their services has never been more acute.

"From providing food to the most disadvantaged in our society, to supporting people through cancer, if charities are not there to meet the need someone will have to pick up that work, or that need will go unmet.”

\section{Social prescribing}

An important link between the NHS and charities comes in the form of social prescribing, a term used to describe the referral of patients from primary care to a wide range of local non-clinical services, from choir groups to financial support. These connections have been formalised in recent years with the introduction of "link workers"-people in the primary care team whose sole role is to take on patients from GPs, assess their needs, and signpost them to services that could help them.

A large proportion of the services that link workers engage with are led by charities. Sam White, a GP link worker for Carnforth and Milnthorpe primary care network, says that she would be lost without local charity services. "A lot of the organisations we refer to are charities that have been massively affected by covid-19, and most have lost $70 \%$ of their funds due to fundraising being unable to go ahead. I worry that if we didn't have these groups I would be lost, as they all do such amazing work."

Nick Grundy, a Teddington GP and chair of the representative group GP Survival, says that he relies on charities, often referring patients to them for mental health support, bereavement, and homelessness. Like many general practices, Grundy's also pays a charity, through its GP federation, to provide its social prescribing link workers.

He says, "I'm worried that, without investment, the charities themselves will cease to exist. That was a concern pre-covid from some of the primary care network pilot sites, and more so now." He adds that clinical commissioning groups need to be prepared to put money into charities where there is increased demand as a result of primary care network referrals or covid-19.

\section{Less money, more work}

One charity that Grundy often refers patients to is RUILS, a group based in Richmond, London, that supports disabled children and adults, as well as elderly people. The charity has worked hard to continue providing normal services-such as its befriending scheme and family support service-while also setting up pandemic services such as providing personal protective equipment (PPE), running a mobile food bank, and delivering prescriptions. their busiest times. During lockdown they have delivered over 1500 food parcels, made over 1300 phone calls, and delivered PPE to GP surgeries throughout the borough.

However, while the group says that it can manage this financial year, it has concerns about what will happen after March 2021. Cathy Maker, its chief executive, says, "Our community fundraising-which includes quizzes, concerts, band nights, and participation events such as marathons-have all been cancelled. We raise about $€ 55$ ooo per year, which funds our counselling services and our befriending for young people.”

Similarly, Marie Curie relies heavily on donations from the public, and the pandemic has significantly affected its fundraising. Wells says, "We have our big Daffodil Appeal in March, and that was cancelled;
For the RUILS staff, the pandemic has been one of 
all of our face to face activity, our events, have been cancelled.”

\section{Fragile system under pressure}

Marie Curie provides frontline services for patients with terminal illness and their families or carers. Around the UK the charity has nurses working in the community, nine hospices, and a telephone helpline for patients, families, and healthcare professionals.

Patients are referred from GPs, district nurses, or hospitals, and the NHS holds contracts with the charity-but the services are only partially NHS funded, and how much the NHS contributes varies between areas.

Wells explains, "Every hospice has a different level of contract, so one may get $80 \%$ of their funding from their local clinical commissioning group and another one may get $20 \%$. It's really inequitable. There needs to be a huge overhaul ... It's a very fragile system that is really going to be tested now."

Tom Nolan, a GP and BMJ clinical editor, says that he has already seen the impact on patients when charities can't provide services face to face, such as choirs and support groups, and he worries about what will happen if they are financially unable to reopen.

"The charity and voluntary sector provide so much value support to patients, particularly in terms of the psychological, social, and practical aspects of living with long term conditions," he says. "I think we've come a long way in primary care in the past few years in linking patients in with this support, and now so much of it isn't available.

“I have several patients who I've tried to refer to charitable sector organisations, where I think their input would make a huge difference to them, but the charities haven't been able to offer support. The demand is still there and it's increasing, but now the supply has crumbled."

\section{Tough decisions ahead}

With so much demand and so little money, charities are having to look at what they can continue doing. Wells says that Marie Curie, even as a large charity with more resilience, is going to have to make "tough decisions."

"Those smaller charities, smaller hospices, and cancer charities-I think there are going to be a lot of closures," she says. "I think there needs to be a more robust funding mechanism for charities providing end of life care. As a charity we want to keep collaborating with the NHS on this, but it needs to be sustainable."

She says that Marie Curie expects a huge backlog of patients who have been unable or too scared to access healthcare during the pandemic, especially those with cancer, chronic kidney disease, heart failure, or chronic respiratory diseases.

"It's all coming. The patients we are seeing out in the community, some of the conditions are very disturbing," she says. "They have missed out on treatment over the last few months and they're frail and vulnerable; they are going to be more prone to flu and other winter pressures.

"All of that backlog is going to see a huge surge in the requirements for our services."

Charity case study: Age UK's “extremely complex and distressing” work

Age UK provides an array of community services. Maria Bunce, head of services for Age UK Isle of Wight, tells The BMJ that the cases seen by its social prescribers and welfare teams are "extremely complex and distressing." On some occasions the teams have needed to call out ambulances to help people who have tried to take their own lives.

The charity has also found itself needing to support people who would normally not fall under its umbrella, including younger families and young single men who have been made redundant. On top of this, many people who lived independently before the pandemic have found that their mobility has decreased so much from a lack of activity during lockdown that they can no longer access the outside world as they did before.

While Bunce's teams are trying to support more people than ever, their paid-for services have been unable to restart, and many of their covid-19 volunteers are returning to work after furlough. "The financial impact of covid-19 and government restrictions has been devastating," she says. "At the beginning of the pandemic and the start of our new financial year we were facing a $f_{300} 000$ deficit budget."

The charity's National Lottery funding for its volunteering service ran out in March 2020, and it has been able to continue through the pandemic only thanks to short term funding from the local authority. "This money is only to the end of March 2021, and they made it clear that they were not going to continue to support this service," says Bunce. "This leaves me fearful for what the future holds, especially if we get a second wave."

\section{Competing interests: None declared.}

Provenance and peer review: Commissioned; not externally peer reviewed.

Institute of Fundraising. Charities are facing a $112.4 \mathrm{bn}$ shortfall in income for the year due to impact of coronavirus. 19 Jun 2020. https://www.institute-of-fundraising.org.uk/news/charitiesare-facing-a-124bn-shortfall-in-income-for-the-year/.

This article is made freely available for use in accordance with BMJ's website terms and conditions for the duration of the covid-19 pandemic or until otherwise determined by BMJ. You may use, download and print the article for any lawful, non-commercial purpose (including text and data mining) provided that all copyright notices and trade marks are retained. 